\title{
INFORMATION SEEKING HABITS OF INFORMATION AND KNOWLEDGE MANAGEMENT STUDENTS: A UNIVERSITY OF JOHANNESBURG CASE STUDY
}

\author{
Author: \\ Cornelius J.P. Niemand

\section{Affiliation:} \\ ${ }^{1}$ Centre of Information \\ and Knowledge \\ Management, University \\ of Johannesburg \\ Johannesburg, South Africa \\ Correspondence to: \\ Cor Niemand \\ email: \\ corn@uj.ac.za

\section{Postal address:} \\ Centre of Information \\ and Knowledge \\ Management, University \\ of Johannesburg, PO \\ Box 524, Auckland Park, \\ Johannesburg 2006, \\ South Africa
}

\section{Keywords:}

digital immigrants; digital native; information behaviour; information management

\section{Dates:}

Received: 02 Nov. 209 Accepted: 28 July 2010 Published: 05 Oct. 2010

How to cite this article: Niemand, C.J.P., 2010, 'Information seeking habits of information and knowledge management students: A University of Johannesburg case study', SA Journal of Information Management 12(1), Art. \#417, 6 pages. DOI: 10.4102/sajim.v12i1.417

This article is available at: http://www.sajim.co.za

C 2010 . The Authors. Licensee: OpenJournals Publishing. This work is licensed under the Creative Commons Attribution License.

\section{ABSTRACT}

According to Uçak (2007:697), 'it is important to explore the information behaviours of the students who are being educated in the field of information management since the role they are going to play in establishing connections between information sources and users is crucial'. This study focuses on the identification of the information seeking behaviour of students in the department of Information and Knowledge Management at the University of Johannesburg, South Africa. The research is based on research conducted at the Hacettep University in Ankara, Turkey.

\section{INTRODUCTION}

According to Prensky (2001), the onset and rapid diffusion of Information and Communication Technology (ICT) in the last decade of the 20th century has brought about a 'singularity' or 'an event which changes things so fundamentally that there is absolutely no going back' in the way the modern man thinks, communicates and interacts within their environment. Nicholas et al. (2003:23) concurs and adds that it is 'not just the number of people using the system that changed so dramatically, the types of people using the system changed dramatically too...'. According to Spink (2004:336), 'the growing complexity of everyday life and work environments often requires people to engage in multitasking behaviours'. Taking this statement into consideration, the importance of determining the information searching habits of students within this hyper-connected environment becomes evident.

\section{Research problem}

According to Uçak (2007)

it is important to explore the information behaviours of the students who are being educated in the field of information management since the role they are going to play in establishing connections between information sources and users is crucial.

(Uçak 2007:697)

The research problem for this study can be formulated as an attempt to explore the information seeking habits of Information and Knowledge Management students at the University of Johannesburg.

In answering the research problem, various concepts relating to information searching behaviour require definition.

\section{INFORMATION SEEKING BEHAVIOUR}

Spink and Cole (2006:25) are of the opinion that human beings have been seeking and using information for survival in various contexts for millennia. According to Johnstone et al. (2004), the rapid diffusion of ICT has created a gap between the production of information via information systems and the processing and use of information by end-users. Johnstone et al. (2004) states that the indentified gap is filled by human behaviour in closing the space between the information generated and information processed. Wilson (2000:49) states that information behaviour is the totality of human behaviour in relation to sources and channels of information, including both active and passive information seeking and information use'. Steinerová and Šušol (2007) recognise this and adds that 'human information behaviour is an integrated activity at various levels of information processing and use'.

Taking this into consideration, Wilson (2000:49) indicates that information seeking behaviour can be defined as the persistent quest for information with a specific goal in mind. Johnstone et al. (2004) states that information seekers will examine the information generated from information systems and will apply cognitive procedures to determine the next step in the information processing cycle. The various steps (including updating, storing, discarding and/or sharing of information) in the information processing cycle will be determined by the information seeker's frame of reference.

Considering the clarification of the concept 'information seeking', the next section will focus on the identification of some categories of information seekers with specific reference to digital natives and digital immigrants within the hyper-connected digital age as postulated by Marc Prensky (2001).

\section{DIGITAL NATIVES VS. DIGITAL IMMIGRANTS}

The information behaviour of Information and Knowledge Management students have been chosen in an attempt to ensure that these students are equipped to link information with the specific use and goals of the individual and/or the organisation. 
Marc Prensky, in his seminal article entitled Digital Natives, Digital Immigrants published in 2001, identified a new class of students entering educational institutions world wide. The following section will define and illustrate the concepts of digital natives and digital immigrants.

\section{Digital immigrants}

It can be stated that world culture has been dominated for the last three decades by the Baby Boomer generation. According to the Oxford English Dictionary Online, a baby boomer is defined as a person born during the post-World War II baby boom (i.e. the years between 1939 and 1945). Gaston (2006:12) adds that 'the baby boomers were the generation that grew up with television and it had an impact in both directions. Television shaped the boomers, and the boomers shaped television'. Those of us who were not born into the digital world, but have at some point later in our lives become fascinated by technology and have adopted many or most aspects of the new technology, are and always will be compared to the baby boomers. Rockett and Powell (2008) are in agreement with the statement postulated by Gaston and add that '[D]igital Immigrants are people who have less experience with technology in general'.

Prensky (2001) identifies the following characteristics or traits of digital immigrants:

- Digital immigrants will use the Internet and World Wide Web as last resort in sourcing information.

- Digital immigrants will read manuals to computer programmes instead of relying on the computer programme to teach the immigrant how to use the computer programme.

- Digital immigrants print emails instead of reading it online.

- Digital immigrants need to edit electronic documents in printed format.

\section{Digital Natives}

Coined by Tapscott (1999) as the 'Net Generation', (from preschool to university-level students), this concept represents the first generation to grow up in a global environment that was already connected and linked before they were born.

They have spent their entire lives surrounded by and using computers, videogames, digital music players, video games, cellular phones, and all the other toys and tools of the digital age.

(Prensky, 2001)

Prensky agrees with Tapscott on the designation of this segment of the global community and adds that because these individuals are all 'native speakers' of the digital language of modern ICT, they can also be referred to as digital natives. Ask any parent, teacher or librarian and they will recognise that the Net generation has, to a large extent, been influenced by the ambient or digital pervasive environment of the 21st century. Observing this new generation within this pervasive environment will reveal a large percentage of these individuals engaging and being in control of the tools and toys of the digital pervasive environment, such as cellular phones, iPods and Sony PlayStation Portables (PSP).

According to Gaston (2006:12), 'in their world, the consumer of information is in charge - not the producer', and states furthermore that, 'a common thread that runs through each of these services (or technologies) is a very high level of nearinstantaneous interactivity controlled by the consumer'. A considerable amount of effort and research has gone into defining the aforementioned individuals:

[T] his group of individuals, born roughly between 1980 and 1994, has been characterized by their familiarity with and reliance on Information and Communications Technologies (ICTs).

(Kennedy, et al. 2006)

For the purpose of this article, the term coined by Marc Prensky will be used to refer to 'Digital Natives'. According to Prensky,
Digital Natives may be defined as the 'native speakers of technology, fluent in the digital language of computers, video games, and the Internet', (Prensky 2005a:8):

The former group's interaction with new technologies can reach durations of 10,000-20,000 hours in the first 20 years of their lives; today's neuroscience tells us that this degree of input is almost certain to have caused measurable physical change to their brains.

(Prensky 2005a:8)

It is therefore evident that digital natives do not have the patience for asynchronous communication and/or searching for information. Before determining the information searching habits of digital natives, it is necessary to identify their characteristics.

\section{Distinguishing characteristics of Digital Natives}

The previous section focussed on describing the concept of a Digital Native. The following section will focus on identifying certain distinguishing characteristics of digital natives and can include some of the markers that distinguish digital natives from digital immigrants (Long, 2005:188 \& van Slyke, 2003):

- Digital natives are used to the speedy delivery of information.

- Digital natives do not need comprehensive instruction on using or interacting with technology. Digital natives collaborate and learn in diverse ways. Learning is not seen as a serious matter any longer.

- Digital natives are capable of multitasking and prefer to do so.

- Digital natives prefer graphics to text.

- Because of the hyper connectedness of the environment wherein digital natives operate, they prefer random access via hypertext.

- The hyper connected environment facilitates network formation and collaboration; it can therefore be stated that the digital native functions best when networking.

- Digital natives thrive on instant gratification and regular rewards.

\section{MULTITASKING AND THE ENGAGEMENT OF DIGITAL NATIVES}

This section will focus on the increased ability of digital natives to multitask and how they engage within their particular environment. Miwa (2001) suggests that information behaviour is fundamentally motivated by imposed, as well as socially and personally generated goals and objectives.

Spink et al. (2002), concurs and adds that the practice of seeking information within the ever changing technological environment may be referred to as, 'multitasking information behaviour'. Taking note of and building on the multitasking behaviour of digital natives, Prensky (2005b:62) writes that all digital natives 'have something in their lives that's really engaging- something that they are good at, something that has an engaging, creative component to it'. This can include mixing, downloading and organising songs and/or PodCasts on their iPods, playing games on their PSPs; creating, uploading and downloading of homemade movies via YouTube or playing online strategy games.

The question arising from this is what are the information seeking habits of digital natives? It should be noted that this article is based on research conducted in the department of Information Management at the Hacettepe University in Ankara, Turkey. Furthermore, this article forms part of a larger study where the results of the Ankara research will be compared to the results obtained from the Johannesburg study.

\section{RESEARCH METHOD}

This study is based on a questionnaire that was distributed to 200 students in the department of Information Management at 


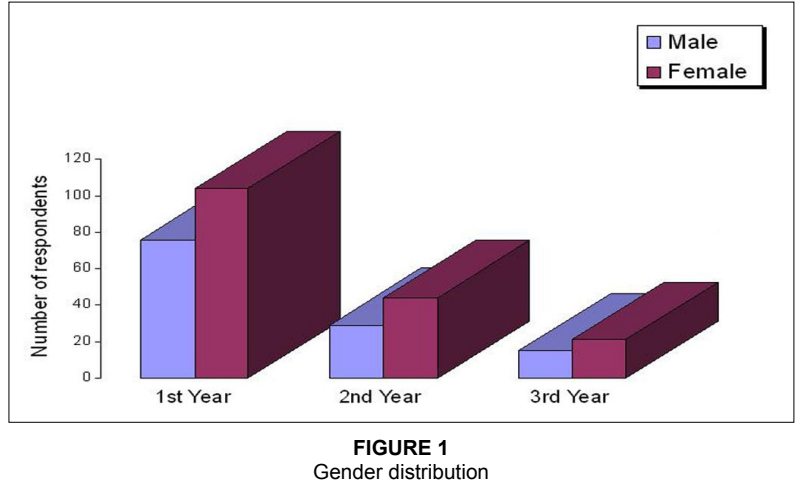

the Hacettepe University in Ankara, Turkey. According to Uçak (2007)

The questions were designed to solicit information about the purpose for which they [students] seek information, how they meet their information needs, their frequency of use and the purpose for which they use the Internet, where they can access the Internet, the qualities they look for in the information they find, which search engine they use most frequently, and, finally, their knowledge and skills in relation to the Internet.

(Uçak 2007:698)

Written permission from the original author was obtained prior to use and distribution of the questionnaire.

In total, 289 students from the University of Johannesburg completed questionnaires, which constitute a representation of $29.34 \%$ of the sample. This number of questionnaires excludes 60 incomplete questionnaires.

\section{EMPIRICAL RESULTS}

A total of 289 completed questionnaires were received. Of the 289 students that completed the questionnaire, 169 students were female $(58.5 \%)$ and 120 were male $(41.5 \%)$ (Figure 1). It is evident from these statistics that the ratio between female and male participants does not vary greatly. It should be noted that the effect of gender on behaviour is not investigated.

The research participants represented different directions of study and included $87 \%$ BA students, 9.6\% B.Com students, $3.1 \%$ BSc students and $0.3 \%$ of students having indicated Other as qualification option. The high ratio of BA students might be attributed to the fact that Information Management is a specific subject within the Arts Faculty (Figure 2).

\section{The need for information}

The question posed to the respondents was to identify, according to importance, the need for information when performing various activities (Figure 3). A total of $48.6 \%$ of the respondents indicated that information was essential to do research, followed by $20 \%$ of the respondents indicating that information is needed

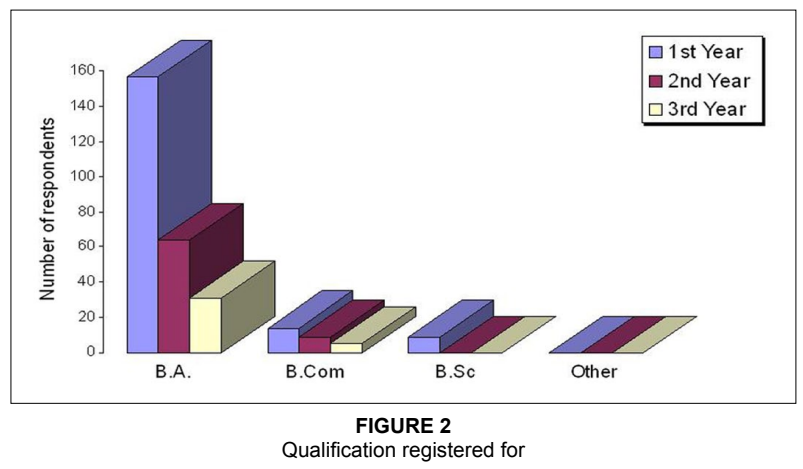

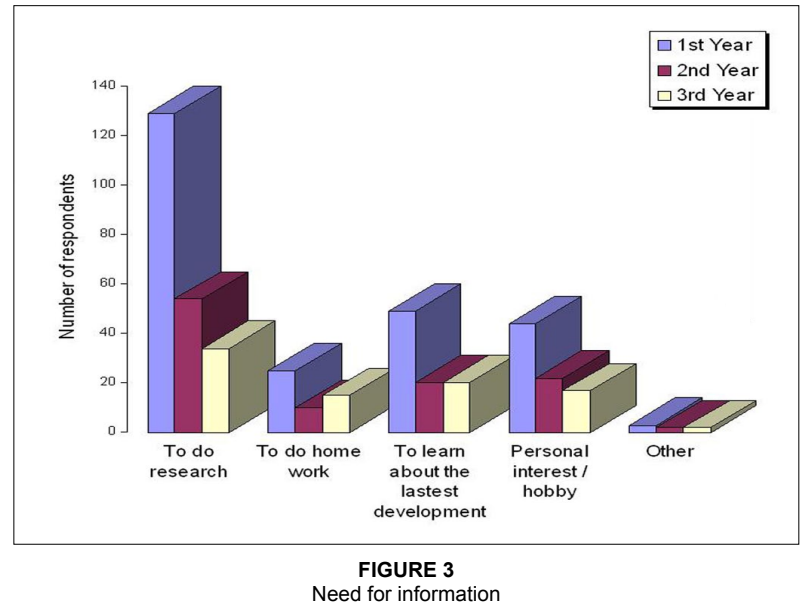

to learn more about the latest developments in their specific area of interest. Only $19 \%$ of the respondents indicated that they obtained information for personal interest. The results obtained from this section of the questionnaire correspond with the results obtained by the study at the Hacettepe University. The majority of the Hacettepe University respondents indicated that they need information in order to complete homework as the primary need for information.

\section{Sources of information}

After ascertaining the need for information, the following question posed to the respondents was to identify the most suitable source of information from a predetermined list of options within the questionnaire. According to Uçak (2007:699), 'the top choice of all classes was the Internet'. The results at the Hacettepe University correlate with the results obtained at the University of Johannesburg especially in terms of the response to this question indicating that $40 \%$ of the respondents meet their information needs while utilising the Internet as primary source. It should be noted that within the University of Johannesburg scenario the Library and Information Centre (LIC) focuses on the education of and use of the Library facilities as part of a first year orientation programme. The results of the LIC strategic initiative are evident if it is considered that $19 \%$ of the respondents see the LIC as a source of information. The use of textbooks is very low in comparison with these information sources. According to the study, only $18 \%$ of the respondents feel that textbooks can be seen as a source of information. These results correlate with the identified attributes of digital natives operating within a hyper connected environment, which refers to utilising the Internet as primary source of information.

\section{Format of information}

Within the hyper connectedness of the environment wherein digital natives operate, digital natives prefer random access to information via the hypertext functionality of the World Wide Web. Uçak (2007:699) states that 'the majority of the [Hacettepe University] students prefer electronic media to printed media'. The results obtained from the questionnaire distributed to

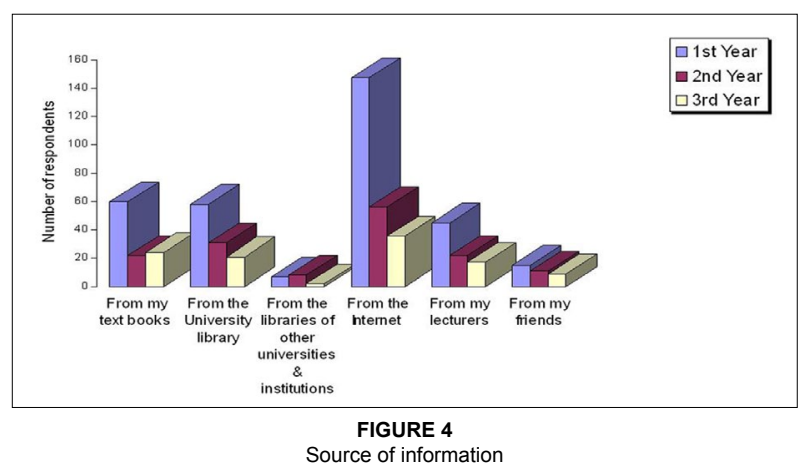




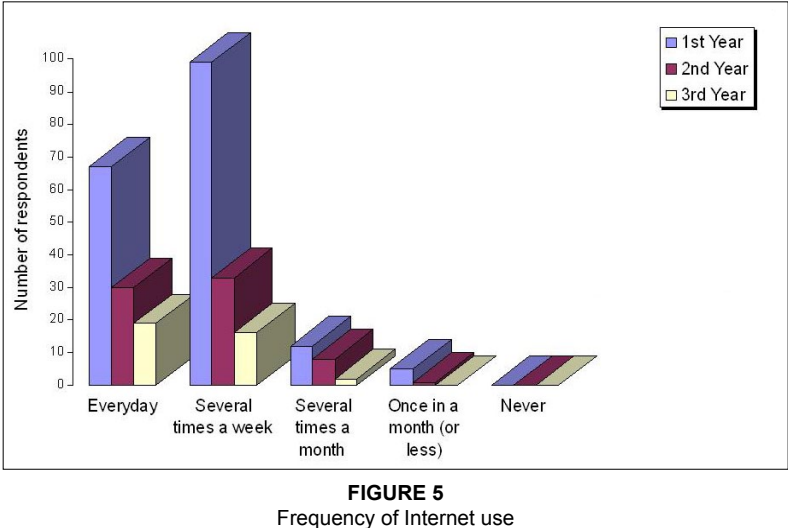

the University of Johannesburg respondents, relating to the preference of the format of the information, corroborates the fact that the Internet and the use of electronic media is preferred if it is considered that $71 \%$ of the respondents preferred information in electronic format.

\section{Frequency of Internet use}

According to the literature reviewed, the near instantaneous nature of the environment frequented by digital natives has created a situation where these individuals have come to expect a very high level of responsiveness in use of online services as part of their day-to-day activities within the hyper connected environment. Taking this into consideration, the department of Information and Knowledge Management, in line with the integrated learning approach set out by the University of Johannesburg, utilises educational technologies to ensure the availability of more than one mode of content delivery or response to the face-to-face lecturing. This is accomplished by integrating and utilising the Black Board Learning System as part of content delivery to the students.

In contrast to the literature reviewed, it should be noted that only $40 \%$ of the respondents at the University of Johannesburg use the Internet on a daily basis (Figure 5), further more $51 \%$ of the respondents indicated that Internet is used several times a week.

\section{Access to the Internet}

The University of Johannesburg is a comprehensive institution, catering for a student population from diverse backgrounds and from varying economic and social standings within South Africa and Africa. Part of the University of Johannesburg policy is to ensure that all students have access to the Internet on the various campuses of the university. This policy has been successful in reaching its goals seeing that $62 \%$ of the respondents utilise the University of Johannesburg's ICT in the form of the computer laboratories to gain access to the Internet (Figure 6). Furthermore, it should be noted that only $20 \%$ of the respondents indicated that Internet access is possible from their homes.

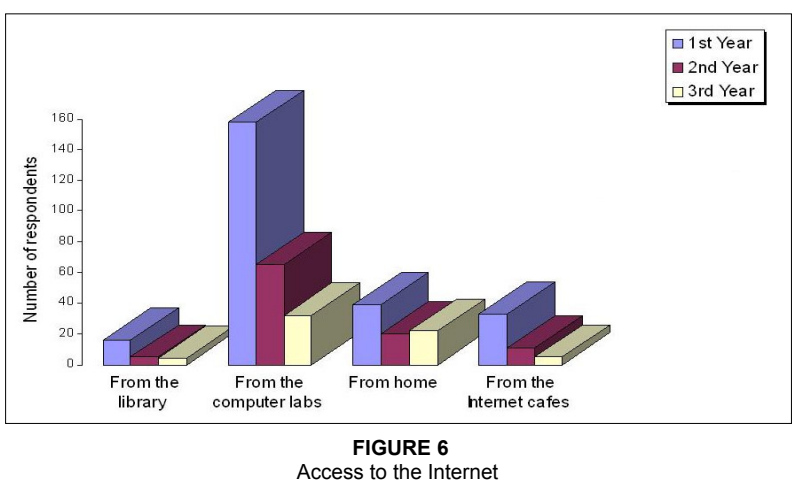

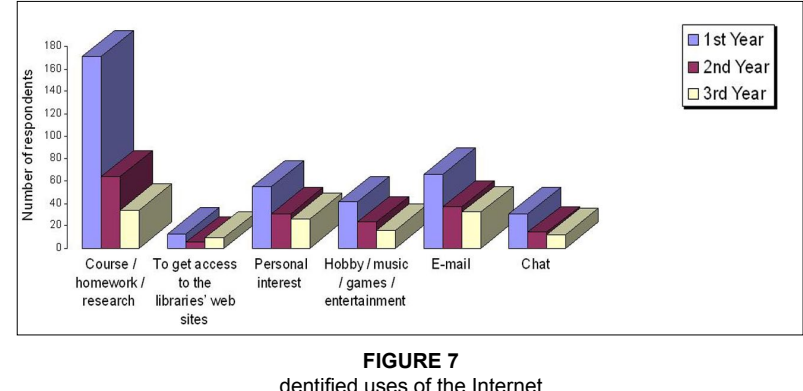

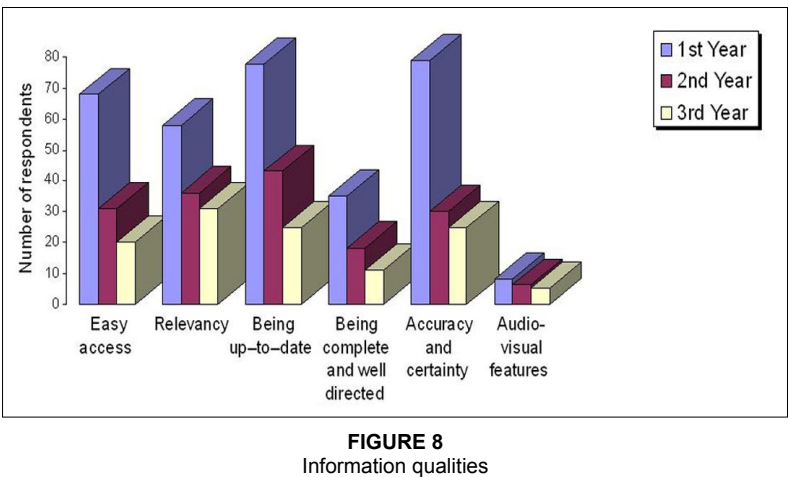

\section{Identified uses of the Internet}

Uçak (2007:700) states that 'the results show that a vast majority of the [Hacettepe University] students use the Internet for their courses and homework assignments'. From the results obtained from the University of Johannesburg respondents, it is evident that the students utilise the Internet to gain access to the World Wide Web to perform various tasks (Figure 7). Forty per cent of the respondents indicated that the Internet is utilised to gain access to information relating to course work, homework and/or research. It is also interesting to note that $20 \%$ of the respondents indicated that the Internet was used to gain access to electronic mail functionality.

\section{Information qualities}

Figure 8 indicates a close relationship between the importance of the identified qualities of information. Only $3 \%$ of the respondents indicated that audio-visual features are important which is in contrast to the research undertaken by Van Slyke in 2003. According to Van Slyke (2003), 'they prefer their graphics before their text rather than the opposite'.

\section{Finding information on the Internet}

As depicted in Figure 9, when the question of how information was retrieved from the Internet was posed to the sample, the majority of the respondents (i.e. 61\%) indicated that search engines was used to source relevant information from the Internet. The results attained from the respondents from the University of Johannesburg correlate to the results attained from the Hacettepe University respondents if it is considered that 'search engines was picked as the answer to this question by the vast majority of students' (Uçak 2007:700). Although 19\% of the respondents see the LIC as a source of information (question 5.2 ), only $7 \%$ utilises the LIC as tool to find information on the Internet.

\section{Preferred search engines}

In an attempt to determine which search engine is preferred by the sample, a question was posed to the respondents in order to identify their favourite search engine(s) when retrieving information from the Internet. The top three identified search engines included (Figure 10): 


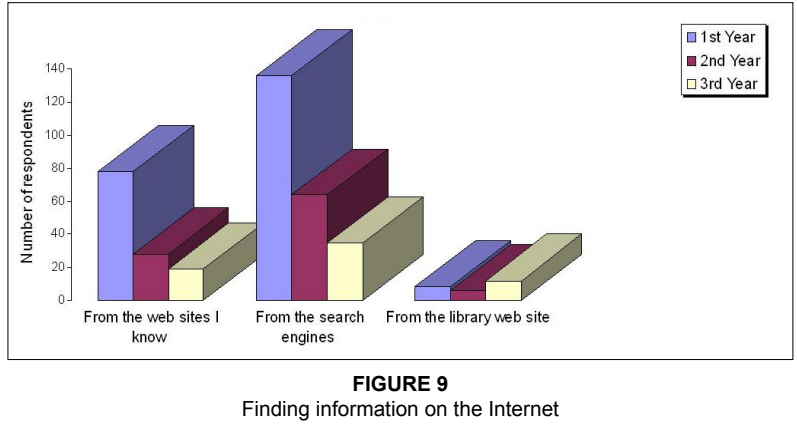

- Google $-74 \%$

- $\mathrm{MSN}-18 \%$

- Ananzi-2\%.

\section{Extent to which search engines meet information needs}

The respondents were asked to indicate if the results obtained from the search engines satisfied their need for information (Figure 11). According to the responses, $41 \%$ of the sample concluded that the results obtained from the search engines completely satisfied their need for information. In contrast, 59\% of the sample indicated that the search engines only partially satisfied their need for information. One first year student indicated that results obtained from search engines did not satisfy their need for information at all.

\section{Internet skills gained}

According to the results gained from the sample, $51 \%$ of the respondents indicate that their basic Internet usage skills were gained through self-exploration (Figure 12). This statement correlates with the results obtained from the respondents at the Hacettepe University. Furthermore, it should be noted that the literature review indicated that digital natives do not need comprehensive instruction on using or interacting with technology and that digital natives tend to learn by exploring. In contrast, only $21 \%$ of the respondents indicated that formal course work exposed and equipped them with the skills to utilise the Internet.

\section{Levels of competency}

The last question in the survey focuss ed on exploring the student's perception of their levels of competency when using the Internet to gain access to the World Wide Web and related application and information (Figure 13). According to Uçak (2007:703) 'the majority of the [Hacettepe University] students see themselves as partially competent in using the Internet'. The results obtained from the University of Johannesburg

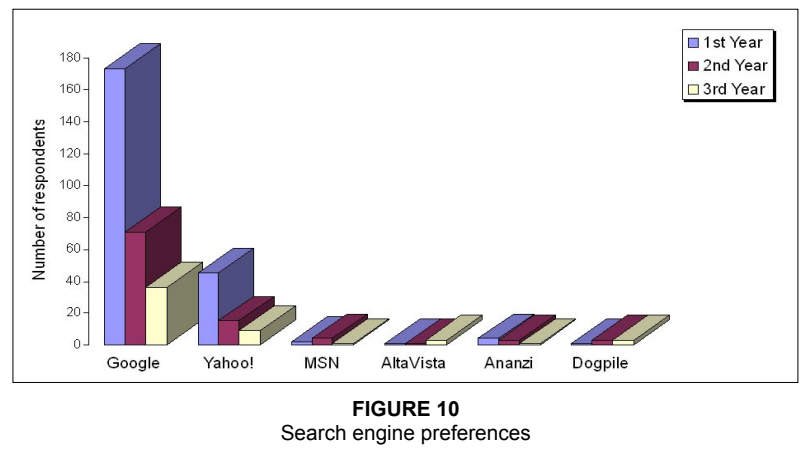

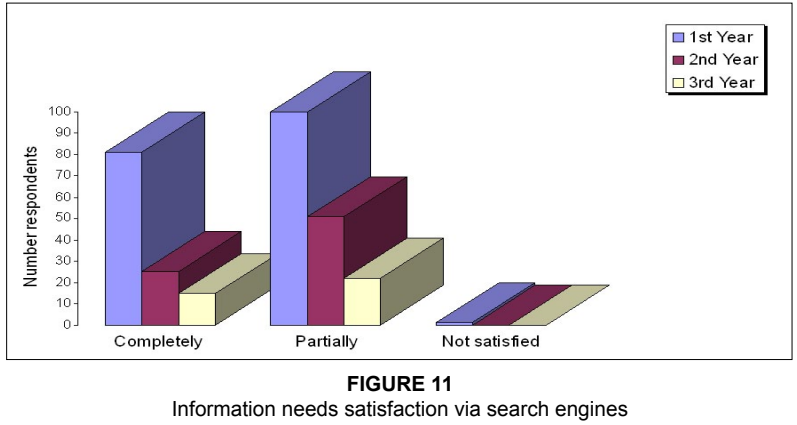

respondents indicate that $53 \%$ of the respondents consider themselves partially competent in utilising the Internet to gain access to information. In contrast, $44 \%$ of the respondents felt competent using the Internet to gain sufficient access to information.

\section{CONCLUSION}

This study is based on a questionnaire that was distributed to 200 students in the department of Information Management at the Hacettepe University in Ankara, Turkey. The core objective of this study was to ascertain the Internet usage habits of students in the Department of Information and Knowledge Management at the University of Johannesburg.

The following conclusion can be made according to the data obtained:

- Respondents indicated the importance of information for research and coursework.

- The most suitable source of information was identified as being the Internet, with the LIC in second position.

- Majority of the respondents preferred information in electronic format.

- Fifty one per cent of the sample accesses the Internet several times a week.

- The University of Johannesburg's ICT infrastructure was identified as the most popular means of accessing the Internet.

- Forty per cent of the respondents indicated that information is needed for course work and research.

- Respondents identified the need for the following in terms of information: (1) easy access, (2) relevancy, (3) being up-todate, (4) being complete and well directed and (5) accuracy and certainty.

- The respondents indicated that Google was the preferred search engine to retrieve information from the Internet.

- Although the majority of the respondents indicated that Internet skills were self-taught, a vast number indicated that the skills sets were inadequate to fulfil their need for information, and in conclusion the respondents felt only partially competent as Internet users.

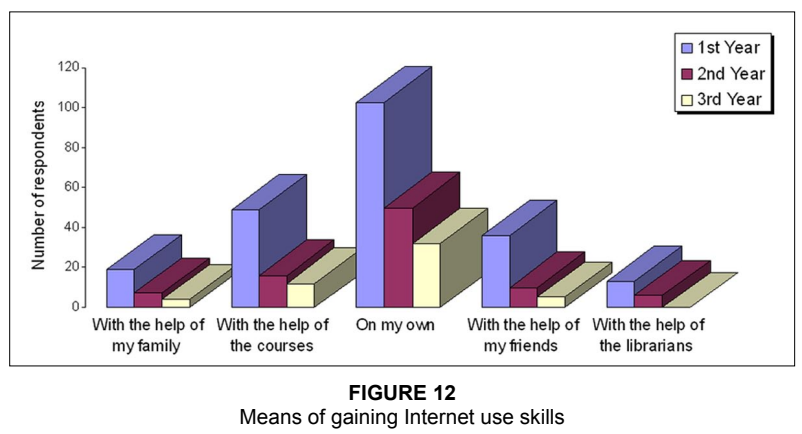




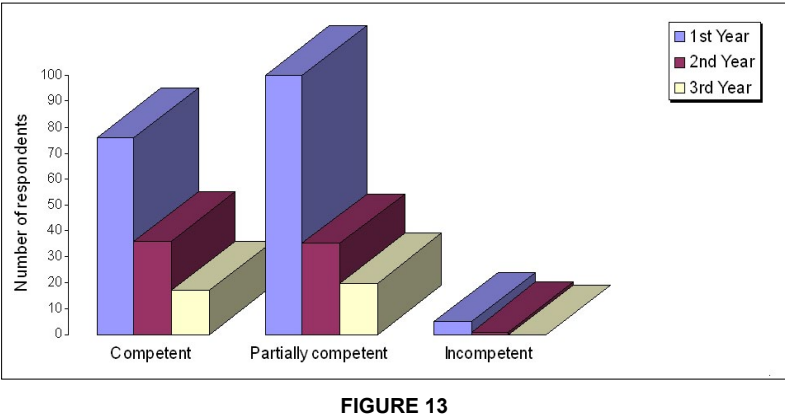

Levels of competency using the Internet

\section{REFERENCES}

Gaston, J., 2006, 'Reaching and teaching the Digital Natives', Library Hi Tech News (3), 12-13.

Johnstone, D., Bonner, M. \& Tate, M., 2004, 'Bringing human information behaviour into information systems research: an application of systems modelling', Information Research 9(4), viewed on 28 October 2009, from http://InformationR. net/ir/9-4/paper191.html.

Kennedy, G., Krause, K., Judd, T., Churchward, A. \& Gray, K. 2006, 'First year students' experience with technology: are they really Digital Natives?', viewed 27 October 2009, from http:// www.bmu.unimelb.edu.au/research/munatives/natives_ report2006.pdf.

Long, S.A., 2005, 'What's new in Libraries? Digital natives: if you aren't one get to know one', New Library World 106 (1210/1211), 187-189.

Miwa, M., 2001, 'User situations and multiple levels of users' goals in information problem-solving processes of AskERIC users', in Vol. 38, American Society for Information Sciences and Technology, Proceedings of the 2001 Annual Meeting of the American Society for Information Sciences and Technology, Silver Spring, MD, 2001, pp. 355-71.

Nicholas, D., Dobrowolski, T., Withey, R., Russell, C., Huntington, P. \& Williams, P, 2003, 'Digital information consumers, players and purchasers: information seeking behaviour in the new digital interactive environment', Aslib Proceedings: New information perspectives 55(1/2) , 23-31

Oxford English Dictionary Online, viewed 28 October 2009, from http://0-dictionary.oed.com.raulib.rau.ac.za/entrance.dtl.
Prensky, M., 2001, 'Digital native, Digital Immigrants', viewed 24 October 2009, from http://pre2005.flexiblelearning.net.au/ projects/resources/Digital_Natives_Digital_Immigrants.pdf.

Prensky,M.,2003,'Overcoming Educators'DigitalImmigrant Accents: A Rebuttal', viewed 10 October 2009, from http:// technologysource.org/article/overcoming_educators_ digital_immigrant_accents/

Prensky, M., 2005a, 'Listen to the Natives' Learning in the Digital Age 63(4) , 8-13.

Prensky, M., 2005b, 'Engage me or enrage me. What today's learners demand', EDUCAUSE, September-October, 40(5), pp. 60-65.

Rockett, D., \& Powell, T., 2008, 'Teaching Technology to Digital Immigrants: Strategies for Success', viewed 28 October 2009, from http://www.umbc.edu/llc/llcreview/2008/2008 teaching_technology.pdf.

Spink, A., Ozmutlu, H.C. \& Ozmutlu, S., 2002, 'Multitasking information seeking and searching processes', Journal of the American Society for Information Science and Technology 53(8), 639-52.

Spink, A., 2004, 'Multitasking information behavior and information task switching: an exploratory study', Journal of Documentation 60(4), 336-351.

Spink, A. \& Cole, C., 2006, 'Human Information Behavior: Integrating Diverse Approaches and Information Use', Journal of the American Society for Information Science and Technology 57(1), 25-35.

Steinerová, J. \& Šušol, J., 2007, 'Users' information behaviour - a gender perspective', Information Research, 12(3), viewed 28 September 2009, from http://InformationR.net/ir/12-3/ paper320.html.

Tapscott, D., 1998, Growing up digital: The Rise of the Net Generation, McGraw-Hill, New York.

Wilson, T.D., 2000, 'Human information behaviour', Informing Science 3(2) , 49-56.

Uçak, N.Ö., 2007, 'Perspectives on Internet use habits of students of the department of Information Management, Hacettepe University, Ankara', The Journal of Academic Librarianship 33(6) , 697-707.

Van Slyke, T., 2003, Digital Natives, Digital Immigrants: Some Thoughts from the Generation Gap, viewed 8 October 2009, from http://technologysource.org/article/digital_ natives_digital_immigrants/ 